\title{
Gastrointestinal Bleeding Rates Among Managed Care Patients Newly Started on COX-2 Inhibitors or Nonselective NSAIDs
}

\author{
KAREN STOCKL, PharmD; LORI CYPRIEN, MS; and EUNICE Y. CHANG, PhD
}

\begin{abstract}
OBJECTIVE: While cyclooxygenase-2 (COX-2) inhibitors were introduced to the U.S. market with the promise of less gastrointestinal (GI) toxicity than nonselective nonsteroidal anti-inflammatory drugs (NSAIDs), additional research is needed to examine this outcome in the naturalistic setting. The objective of this study was to examine whether use of COX-2 inhibitors is associated with reduced risk of $\mathrm{GI}$ bleed in a managed care population.
\end{abstract}

METHODS: Adult patients in a multistate managed care organization that were initiated on a nonselective NSAID between January 1999 and August 2002 were identified and matched using propensity scoring with patients in the same managed care organization that were initiated on a COX-2 inhibitor. Matching variables included age, gender, geographical state, comorbidity index, corticosteroid use, warfarin use, arthritis indication, and history of recent Gl bleed. Patients were followed until they switched or discontinued their NSAID or COX-2 inhibitor, disenrolled from the health plan, developed a GI bleed, or reached the end of the 1-year follow-up period. A Gl bleed was defined as an inpatient hospitalization for GI bleed or at least 2 medical claims with a primary diagnosis for Gl bleed. The relative risk (RR) of Gl bleed was calculated using proportional hazards regression.

RESULTS: Overall, 35,007 pairs of COX-2 inhibitor and nonselective NSAID users were evaluated. Mean age was 63 years, and $65 \%$ were female. There were 375 cases of Gl bleed among 19,201 follow-up years for COX-2 users (19.5 cases per 1,000 person-years) versus 228 cases of GI bleed among 12,680 follow-up years for NSAID users (18.0 cases per 1,000 person-years). The risk of Gl bleed was not significantly different for COX-2 users compared with nonselective NSAID users (RR 1.07; 95\% confidence interval [Cl], 0.90-1.26). Even among high-risk patients, there was no reduction in the risk of a Gl bleed among users of COX-2 inhibitors (RR 0.995; 95\% Cl, $0.84-1.19$ ).

CONCLUSION: Overall, within this managed care population, COX-2 inhibitor users did not have a reduced risk of a GI bleed compared with patients with similar baseline characteristics using nonselective NSAIDs.

KEYWORDS: Cyclooxygenase, Nonsteroidal anti-inflammatory drugs, Gastrointestinal bleed, Drug therapy

J Manag Care Pharm. 2005;11(7):550-58

Note: An editorial on the subject of this article appears on pages 590-93 of this issue.

Authors

KAREN STOCKL PharmD, was a research scientist, health economics and outcomes research, Prescription Solutions, Costa Mesa, California, at the time of this study; LORI CYPRIEN, MS, is a statistician, health economics and outcomes research; EUNICE Y. CHANG, PhD, is chief statistician, health informatics and outcomes research, Prescription Solutions, Costa Mesa, California.

AUTHOR CORRESPONDENCE: Karen Stockl, PharmD, clo Eunice Y. Chang, PhD, Chief Statistician, Health Informatics and Outcomes Research, Prescription Solutions, 3515 Harbor Blvd., Mail Stop LC07-264, Costa Mesa, CA, 92626. Tel: (714) 825-3732; Fax: (714) 825-3742; E-mail: information@rxsolutions.com Copyright $\odot$ 2005, Academy of Managed Care Pharmacy. All rights reserved.
$\mathrm{R}$ ecent reports of adverse cardiovascular outcomes with two of the cyclooxygenase-2 (COX-2) inhibitors have placed the risk-benefit profile of these COX-2 inhibitors under public scrutiny; both of the COX-2 inhibitors have subsequently been withdrawn from the U.S. market). ${ }^{1-3}$ As a result, clinicians have been encouraged to weigh the potential benefits and risks of the nonsteroidal anti-inflammatory (NSAID) medications prior to prescribing them. ${ }^{4}$ Managed care has been particularly interested in examining the risks, benefits, and cost-effectiveness of the COX-2 inhibitors. ${ }^{5-8}$ The present study was designed to evaluate whether the use of COX-2 inhibitor medications was beneficial in preventing gastrointestinal (GI) bleeds compared with the use of nonselective NSAIDs in the naturalistic managed care setting.

The early reported results of controlled clinical studies suggested that the COX-2 inhibitors may have less GI toxicity than nonselective NSAIDs, ${ }^{9-14}$ but the U.S. Food and Drug Administration (FDA) permitted this claim only for rofecoxib, which was later withdrawn from the U.S. market, on September 30, 2004, due to adverse cardiovascular events. ${ }^{1,15}$

In actual clinical practice, patients' medication use is not monitored as closely as in clinical trials. As a result, patients may not take their COX-2 inhibitor medication under the same conditions as those studied (e.g., they may take higher doses than those prescribed or they may use COX-2 inhibitors concomitantly with gastrotoxic substances such as alcohol), which may lead to different outcomes than those observed in clinical trials. Furthermore, the population prescribed COX-2 inhibitors in clinical practice may have more risk factors for a GI bleed than the population selected to test the COX-2 inhibitors in clinical trials.

The objective of this analysis was to examine whether a managed care population of patients who used COX-2 inhibitors in a naturalistic setting actually did have a reduced occurrence of GI bleed compared with a population of patients with similar baseline characteristics who received nonselective NSAIDs.

\section{Methods}

This was a retrospective analysis of electronic pharmacy and medical administrative claims from a large managed care organization and Prescription Solutions, a pharmacy benefits and medical management company. Longitudinal claims data were used from health plans (private as well as Medicare + Choice [now Medicare Advantage]) within California, Oklahoma, Oregon, Texas, and Washington, which consist of approximately 2.7 million 
lives. This database has been used in previous research studies. ${ }^{16-20}$

An estimated two thirds of members within this managed care population were subject to prior authorization for COX-2 drugs that required patients to meet certain clinical characteristics prior to receiving authorization for coverage of a COX-2 inhibitor. Prior authorization approval for a COX-2 inhibitor was more likely to be given to patients with older age, a diagnosis of rheumatoid arthritis or osteoarthritis, history of GI bleed, and/or concomitant use of oral corticosteroids or warfarin.

\section{Patient Identification and Matching}

Adult patients (aged 18 years or older) initiated on a COX-2 inhibitor (generic product identifier [GPI] code 661005xx, which included rofecoxib, celecoxib, and valdecoxib) or a nonselective NSAID (GPI code 661000xx, which consisted of all prescription NSAIDs other than those classified as COX-2 inhibitors) during the 44-month period from January 1, 1999, through August 31, 2002 (identification period), were identified. The index date was defined as the date of each patient's first prescription fill of a COX-2 inhibitor or nonselective NSAID during the identification period. Patients were excluded from the analysis if they had a pharmacy claim for a COX-2 inhibitor or a nonselective NSAID during the 6-month period prior to their index date (i.e., the preperiod) or if they were not continuously enrolled in the health plan during the preperiod and at least 3 months after the index date. The first (earliest) patient that could have been identified would have had an index date on January 1, 1999, and a preperiod starting July 1, 1998. Hence, some patients' preperiods may have started prior to the FDA approval of celecoxib. Celecoxib, the first COX-2 inhibitor to be approved, was approved on December 31, 1998. ${ }^{21}$

From these identified patients, the final study cohort was obtained by matching patients who received a nonselective NSAID on the index date with those who received a COX-2 inhibitor on the index date on a 1:1 basis using the propensity score method. ${ }^{22}$ A propensity score, which represents the likelihood of receiving a COX-2 inhibitor rather than a nonselective NSAID, was determined for each patient. Patients were matched based on their propensity score.

The independent variables that were used to calculate the propensity score included demographics (age at index date, gender, geographical state of the health plan), Charlson Comorbidity Index ${ }^{23}$ (calculated during the preperiod using a method adapted for electronic claims databases), ${ }^{24}$ and the following GI bleed risk factors (measured during the preperiod): a prescription fill of a corticosteroid (GPI codes 2210xx, 2220xx, 2200xx), a prescription fill of warfarin (GPI code 83200030), a medical claim representing a recent GI bleed (Table 1), history of a GI bleed-related inpatient hospitalization (i.e., an inpatient hospitalization with at least a 1-day length of stay and a diagnosis code representing a GI bleed, Table 1), and arthritis indication (osteoarthritis [International Classification of Diseases, 9th Revision,

\section{TABLE 1 Diagnosis Codes Representing Gastrointestinal Bleed}

\begin{tabular}{ll}
\hline ICD-9-CM Code & Description \\
\hline 530.2 & Ulcer of esophagus \\
$531 . x x$ & Gastric ulcer \\
$532 . x x$ & Duodenal ulcer \\
$533 . x x$ & Peptic ulcer site unspecified \\
$534 . x x$ & Gastrojejunal ulcer \\
$578 . x x$ & Gastrointestinal hemorrhage \\
\hline ICD-9-CM=International Classification of Diseases, 9th Revision, Clinical \\
Modification.
\end{tabular}

Clincial Modification (ICD-9-CM) code 715.xx], rheumatoid arthritis [ICD-9-CM code 714.xx], or neither). Patients diagnosed with both osteoarthritis and rheumatoid arthritis were classified into the rheumatoid arthritis group. If more than 1 patient who received a nonselective NSAID was identified as a match, 1 patient was selected at random to be included in the final study cohort. Patients who could not be matched were excluded from the analysis.

Patients in the matched COX-2 inhibitor and nonselective NSAID cohorts were further stratified according to their GI risk. Patients were considered high-risk if they met any of the following criteria: (1) age greater than 65 years; (2) GI-bleed-related inpatient hospitalization during the preperiod; (3) pharmacy claim for warfarin (GPI code 83200030) during the preperiod; or (4) pharmacy claim for a corticosteroid (GPI codes $2210 \mathrm{xx}$, 2220xx, 2200xx) during the preperiod. All other patients were classified as low-risk.

\section{Outcome Measures}

The primary outcome of interest was the risk of developing a GI bleed over the follow-up period. Patients were followed until the first occurrence of one of the following events: (1) patient discontinued (as defined below) the index COX-2 inhibitor or nonselective NSAID medication; (2) crossover of medication of interest (patient filled a prescription for a study medication in a class [COX-2 inhibitor or nonselective NSAID] other than their index class of medication); (3) patient disenrolled from the health plan; (4) patient had a GI-bleed-related inpatient hospitalization; (5) patient had 2 medical claims with a primary (first-listed) diagnosis for Gl bleed (Table 1) during the follow-up period (where the event date was defined as the date of the first of the 2 claims); or (6) the end of the 1-year follow-up period. A discontinuation was defined as a gap of at least 60 days between the run-out date of the last index COX-2 inhibitor or nonselective NSAID medication fill (fill date plus the days of supply of that last prescription) and the end of the follow-up period. Patients were considered to have a GI bleed event if they experienced a GI bleed-related inpatient hospitalization (event 4 above) or had 2 medical claims with a primary diagnosis for a GI bleed (event 5 above) within the follow-up time frame. 


\section{FIGURE 1 Study Population Identification}

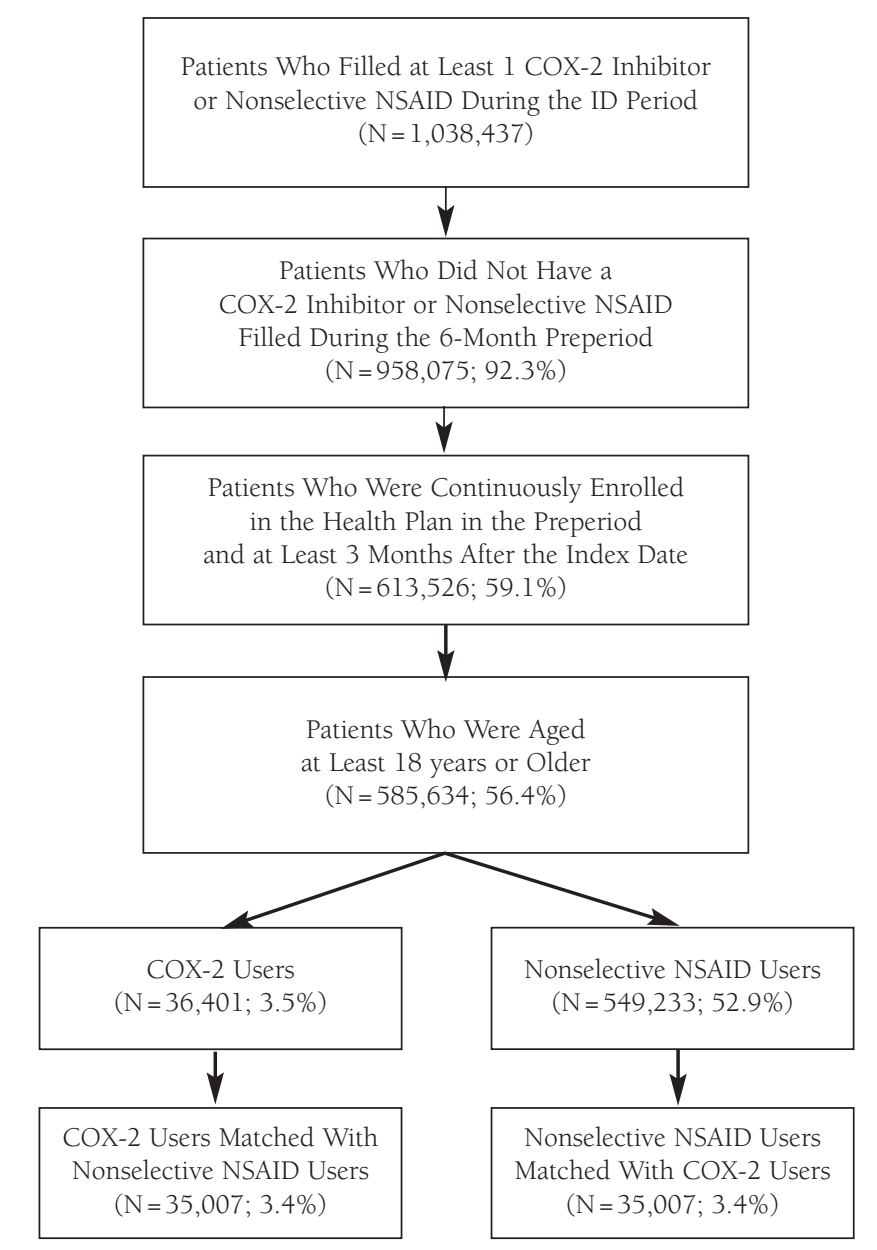

COX-2 = cyclooxygenase $-2 ;$ GI = gastrointestinal NSAID = nonsteroidal antiinflammatory drug.

To account for the different lengths of follow-up, the number of GI bleed cases per 1,000 person years was calculated by dividing the number of patients who experienced the GI bleed event during the follow-up period by the sum of each patient's observed follow-up time (in years) and then multiplying by 1,000.

\section{Statistical Analysis}

Statistical analyses were performed using SAS version 9.1 (SAS Institute Inc., Cary, NC). Chi-square tests and $t$ tests were used to compare baseline demographics and clinical characteristics between the COX-2 inhibitor and nonselective NSAID cohorts. Propensity score calculations were conducted using logistic regression. Two-way interactions between independent variables were tested and only significant interactions $(P<0.05)$ were included in the final propensity model. The propensity score for each patient was rounded to 0.0001 for matching. Proportional hazards regression was used to determine relative risk of a GI bleed event for the 2 cohorts, to study the relationship between the event and specific risk factors, and to adjust for baseline differences between the cohorts. Risk factors included in the model were age, gender, state of health plan, preperiod Charlson Comorbidity Index, preperiod corticosteroid use, preperiod warfarin use, preperiod diagnosis of GI bleed in any diagnostic field, and preperiod rheumatoid or osteoarthritis indication. Separate models were created for the total study population, the low-risk population, and the high-risk population. Only the main effects were included in the models (interaction terms were not tested for inclusion).

To adjust for baseline differences in the use of gastroprotective agents between the cohorts, additional proportional hazards regression models were performed after adding preperiod use of a gastroprotective agent as a variable. To assess the proportional hazards assumption, a plot of the scaled Schoenfeld residuals by transformed time for each risk factor was investigated and a test of zero slope of the plot was conducted. ${ }^{25-27}$ Nonzero slope would indicate a violation of the proportional hazards assumption. If nonproportional hazards were found for some risk factors, then stratified proportional hazards regressions were conducted to evaluate whether the GI bleed event outcome was changed by this stratification. All statistical tests were 2-sided with an alpha of 0.05 .

\section{Results}

There were 1,038,437 patients who filled at least 1 COX-2 inhibitor or nonselective NSAID during the identification period (Figure 1). Among them, 80,362 (7.7\%) were excluded because they had a pharmacy claim for a COX-2 inhibitor or nonselective NSAID during the preperiod, and 344,549 were excluded because they were not continuously enrolled in the preperiod and at least 3 months after the index date. An additional 27,892 patients were excluded because they were younger than 18 years.

Overall, 585,634 eligible patients were identified; 36,401 (6.2\%) used COX-2 inhibitors and 549,233 (93.8\%) used nonselective NSAIDs. A total of 70,014 patients $(35,007$ pairs of COX-2 inhibitor users and nonselective NSAID users) were matched according to propensity score and included in the final study cohort.

Demographics and clinical characteristics were similar for COX-2 inhibitor and nonselective NSAID cohorts (Table 2), with the exception of a lower percentage of COX-2 inhibitor users participating in a Medicare + Choice health plan $(53.1 \%$ versus $55.7 \%, P<0.001$ ); health plan type was not one of the variables included in the propensity score match. When the populations were stratified according to low and high GI bleed risk, there were also statistical differences in the mean age for the COX-2 inhibitor and nonselective NSAID cohorts, which were apparently due to the large sample size since the mean 
TABLE 2 Baseline Demographics and Clinical Characteristics of Study Population*

\begin{tabular}{|c|c|c|c|c|c|c|}
\hline & \multicolumn{2}{|c|}{ Total Population } & \multicolumn{2}{|c|}{ Low-Risk Population } & \multicolumn{2}{|c|}{ High-Risk Population $\dagger$} \\
\hline & $\begin{array}{c}\text { COX-2 } \\
\text { Inhibitor } \\
(\mathrm{N}=35,007)\end{array}$ & $\begin{array}{l}\text { Nonselective } \\
\text { NSAID } \\
(\mathrm{N}=35,007)\end{array}$ & $\begin{array}{c}\text { COX-2 } \\
\text { Inhibitor } \\
(\mathrm{N}=14,897)\end{array}$ & $\begin{array}{l}\text { Nonselective } \\
\text { NSAID } \\
(\mathrm{N}=14,650)\end{array}$ & $\begin{array}{c}\text { COX-2 } \\
\text { Inhibitor } \\
(\mathrm{N}=20,110)\end{array}$ & $\begin{array}{c}\text { Nonselective } \\
\text { NSAID } \\
(\mathrm{N}=20,357)\end{array}$ \\
\hline Age, mean (SD) & $63.4(16.3)$ & $63.3(16.3)$ & $48.9(10.5) \|$ & $48.6(10.6) \|$ & $74.2(10.3) \|$ & $73.9(10.5) \|$ \\
\hline Female gender & $22,909(65.4)$ & $22,906(65.4)$ & $9,219(61.9)$ & $9,142(62.4)$ & $13,690(68.1)$ & $13,764(67.6)$ \\
\hline $\begin{array}{l}\text { State of health plan } \\
\text { California } \\
\text { Oklahoma } \\
\text { Oregon } \\
\text { Texas } \\
\text { Washington }\end{array}$ & $\begin{array}{r}24,090(68.8) \\
1,771(5.1) \\
1,555(4.4) \\
3,843(11.0) \\
3,748(10.7)\end{array}$ & $\begin{array}{r}23,936(68.4) \\
1,756(5.0) \\
1,560(4.5) \\
3,961(11.3) \\
3,794(10.8)\end{array}$ & $\begin{array}{r}10,726(72.0) \\
951(6.4) \\
724(4.9) \\
1,373(9.2) \\
1,123(7.5)\end{array}$ & $\begin{array}{r}10,506(71.7) \\
902(6.2) \\
729(5.0) \\
1,361(9.3) \\
1,152(7.9)\end{array}$ & $\begin{array}{r}13,364(66.5) \\
820(4.1) \\
831(4.1) \\
2,470(12.3) \\
2,625(13.1)\end{array}$ & $\begin{array}{r}13,430(66.0) \\
854(4.2) \\
831(4.1) \\
2,600(12.8) \\
2,642(13.0)\end{array}$ \\
\hline Medicare + Choice health plan $(\%) \ddagger$ & $18,574(53.1) \mathrm{II}$ & $19,488(55.7) \mathrm{I}$ & 987 (6.6)I & $1,139(7.8) \mathbb{I}$ & $17,587(87.5) \mathrm{q}$ & $18,349(90.1) \mathbb{I}$ \\
\hline Charlson Comorbidity Index, mean (SD) & $0.29(0.95)$ & $0.30(0.98)$ & $0.15(0.69)$ & $0.15(0.71)$ & $0.39(1.09)$ & $0.40(1.12)$ \\
\hline $\begin{array}{l}\text { Arthritis indication } \\
\text { Rheumatoid arthritis§ } \\
\text { Osteoarthritis } \\
\text { None }\end{array}$ & $\begin{array}{r}1,040(3.0) \\
5,788(16.5) \\
28,179(80.5)\end{array}$ & $\begin{array}{r}1,015(2.9) \\
5,802(16.6) \\
28,190(80.5)\end{array}$ & $\begin{array}{r}276(1.9) \\
1,224(8.2) \\
13,397(89.9)\end{array}$ & $\begin{array}{r}283(1.9) \\
1,189(8.1) \\
13,178(90.0)\end{array}$ & $\begin{array}{r}764(3.8) \\
4,564(22.7) \\
14,782(73.5)\end{array}$ & $\begin{array}{r}732(3.6) \\
4,613(22.7) \\
15,012(73.7)\end{array}$ \\
\hline Warfarin use & $2,264(6.5)$ & $2,262(6.5)$ & 0 & 0 & $2,264(11.3)$ & $2,262(11.1)$ \\
\hline Corticosteroid use & $3,385(9.7)$ & $3,406(9.7)$ & 0 & 0 & $3,385(16.8)$ & $3,406(16.7)$ \\
\hline Medical claim for GI bleed (any field) & $843(2.4)$ & $808(2.3)$ & $252(1.7)$ & $223(1.5)$ & $591(2.9)$ & $585(2.9)$ \\
\hline Inpatient hospitalization for GI bleed & $132(0.4)$ & $119(0.3)$ & 0 & 0 & $132(0.7)$ & $119(0.6)$ \\
\hline \multicolumn{7}{|c|}{ 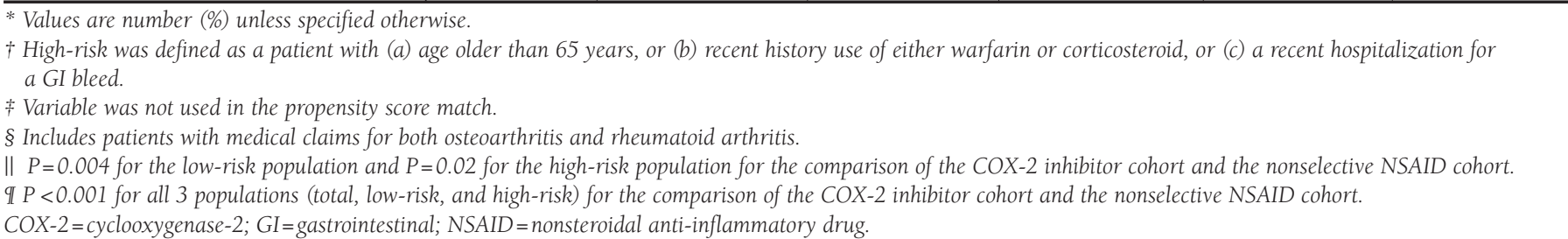 } \\
\hline
\end{tabular}

( \pm standard deviation) age was similar for the 2 cohorts $(48.9 \pm$ 10.5 years versus $48.6 \pm 10.6$ years, respectively, for low-risk users, $P=0.004 ; 74.2 \pm 10.3$ years versus $73.9 \pm 10.5$ years, respectively, for high-risk users, $P=0.02$ ). Although statistically significant, the small difference in age between the groups probably is not clinically meaningful. During the preperiod, $17.5 \%$ of COX-2 inhibitor users and $7.8 \%$ of nonselective NSAID users filled at least 1 prescription for a GI protective agent (i.e., a proton pump inhibitor or misoprostol, GPI codes 49250030xx, 6610990220, 4927xx, 6610990242).

Subjects in the nonselective NSAID cohort had a shorter follow-up time (average 4.3 months per patient or 12,680 personyears, Table 3) than subjects in the COX-2 inhibitor cohort (average 6.6 months per patient or 19,201 person-years).

A GI bleed event (defined as a GI-bleed-related inpatient hospitalization or at least 2 medical claims with a primary diagnosis for GI bleed) was noted in 19.5 patients per 1,000 person years in the COX-2 inhibitor cohort and 18.0 patients per 1,000 person years in the nonselective NSAID cohort (Table 3). The time to GI bleed event (median and mean) was shorter for the nonselective NSAID cohort than for the COX-2 inhibitor cohort.
The proportions of patients in each cohort whose follow-up period ended due to reasons other than a GI bleed event are described below. Compared with COX-2 inhibitor users, a greater percentage of nonselective NSAID users discontinued their index medication (82.2\% versus 63.6\%), while a smaller percentage of nonselective NSAID users had a crossover of medication of interest (1.2\% versus $4.6 \%$ ). Nonselective NSAID users were also less likely than COX-2 inhibitor users to disenroll from the health plan (15.8\% versus $30.1 \%$ ) but were less likely to reach the end of the 1-year follow-up period than COX-2 inhibitor users ( $0.2 \%$ versus $0.6 \%$ ).

Patients who had a GI bleed event had a mean age of $75.1 \pm$ 11.3 years and $61 \%$ were female. The mean Charlson Comorbidity Index was $0.84 \pm 1.57$. Among these patients, $15.3 \%$ used warfarin and $13.1 \%$ used corticosteroids during the preperiod. During the preperiod, $16.1 \%$ of these patients had a medical claim for a GI bleed (any field), and 3.6\% had an inpatient hospitalization for a GI bleed. At the end of follow-up, use of a GI protective agent was observed in $21.1 \%$ of COX-2 inhibitor and $8.8 \%$ of nonselective NSAID users who had a GI bleed event compared with $8.1 \%$ of COX-2 inhibitor and $4.0 \%$ 


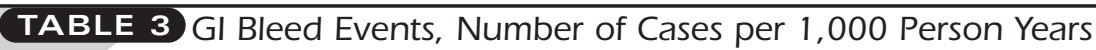

\begin{tabular}{|c|c|c|c|c|c|c|c|}
\hline & & \multicolumn{2}{|c|}{ Total Population } & \multicolumn{2}{|c|}{ Low-Risk Population } & \multicolumn{2}{|c|}{ High-Risk Population* } \\
\hline & & $\begin{array}{c}\text { COX-2 } \\
\text { Inhibitor } \\
(\mathrm{N}=35,007) \\
\end{array}$ & $\begin{array}{c}\text { Nonselective } \\
\text { NSAID } \\
(\mathrm{N}=35,007) \\
\end{array}$ & $\begin{array}{c}\text { COX-2 } \\
\text { Inhibitor } \\
(\mathrm{N}=14,897) \\
\end{array}$ & $\begin{array}{c}\text { Nonselective } \\
\text { NSAID } \\
(\mathrm{N}=14,650) \\
\end{array}$ & $\begin{array}{c}\text { COX-2 } \\
\text { Inhibitor } \\
(\mathrm{N}=20,110) \\
\end{array}$ & $\begin{array}{c}\text { Nonselective } \\
\text { NSAID } \\
(\mathrm{N}=20,357) \\
\end{array}$ \\
\hline \multicolumn{2}{|c|}{ Sum of patients' follow-up years } & 19,201 & 12,680 & 6,605 & 5,003 & 12,596 & 7,677 \\
\hline \multirow{4}{*}{$\begin{array}{l}\text { Inpatient hospitalization } \\
\text { or primary diagnosis for } \\
\text { GI bleed on } 2 \text { medical } \\
\text { claims }\end{array}$} & Number of cases & 375 & 228 & 51 & 19 & 324 & 209 \\
\hline & $\begin{array}{l}\text { Number of cases per } 1,000 \\
\text { person-years }\end{array}$ & 19.5 & 18.0 & 7.7 & 3.8 & 25.7 & 27.2 \\
\hline & Median time to event (days) $\dagger$ & 84.0 & 61.5 & 102.0 & 78.0 & 77.0 & 61.0 \\
\hline & Mean time to event (days) $\dagger$ & 111.5 & 100.9 & 117.3 & 110.6 & 110.6 & 100.0 \\
\hline
\end{tabular}

* High-risk was defined as a patient with (a) age older than 65 years, or (b) recent history use of either warfarin or corticosteroid, or (c) a recent hospitalization for a GI bleed.

$\dagger$ Median and mean time to event were measured among those patients who had a GI bleed event during the follow-up period.

COX-2 = cyclooxygenase $-2 ;$ GI = gastrointestinal; NSAID = nonsteroidal anti-inflammatory drug.

of nonselective NSAID users who did not have a GI bleed event.

Proportional hazards regression was conducted to determine the relative risk of a GI bleed event for the 2 cohorts (accounting for different patient follow-up times and adjusting for baseline characteristics) and to study the relationship between the event and specific risk factors (Table 4). Among the total study population and the high-risk population, patients who received a COX-2 inhibitor did not have a lower relative risk of having a GI bleed event (defined as an inpatient hospitalization for GI bleed or at least 2 medical claims with a primary diagnosis for GI bleed) compared with patients who received a nonselective NSAID. Other factors that were significant predictors of a GI bleed event were older age, male gender, state of health plan (California versus Texas), higher Charlson Comorbidity Index, use of warfarin, and a history of GI bleed. For low-risk patients, those who received a COX-2 inhibitor had a higher relative risk of a GI bleed event compared with patients who received nonselective NSAIDs. Male gender, higher Charlson Comorbidity Index, history of GI bleed, and diagnosis of osteoarthritis were found to be additional risk factors, but age and state of health plan were not.

Within the total study population and the high-risk population, the test of the proportional hazards assumption (using the plot of the scaled Shoenfeld residuals by transformed time for each risk factor) revealed significant evidence of nonproportional hazards for the risk factor of a preperiod history of GI bleed. Stratification by preperiod history of GI bleed did not significantly alter the hazard ratio for the comparison between COX-2 inhibitors and nonselective NSAIDs or for the other specific risk factors in the model. Within the low-risk population, the test of the proportional hazards assumption found significant evidence of nonproportional hazards for the risk factor of arthritis indication on a medical claim. Stratification by arthritis indication did not significantly alter the other hazard ratios in the model.

Since a higher proportion of patients treated with a COX-2 inhibitor used a gastroprotective agent during the preperiod, additional proportional hazards regression models were performed to evaluate whether the GI bleed outcome changed after adjusting for differences in preperiod use of a gastroprotective agent (Table 5). In the total study population and the high-risk population, the hazard ratios changed slightly, but the overall study findings and level of significance were not altered. However, in the low-risk population, patients who received a COX-2 inhibitor no longer had a significantly greater risk of having a GI bleed event compared with patients who received a nonselective NSAID after adjusting for preperiod use of a gastroprotective agent. In all 3 study populations (total population, low-risk, and high-risk), preperiod use of gastroprotective agents was a factor associated with a higher risk of a GI bleed during follow-up. Similar to the previous models, stratified models were performed because there was evidence of nonproportional hazards for the risk factor of history of GI bleed for the total population and the high-risk population and for the risk factor of arthritis indication for the low-risk population. The stratified models did not significantly alter the hazard ratios.

\section{Discussion}

In this retrospective study of a population of COX-2 inhibitor users who were matched to nonselective NSAID users with similar baseline characteristics, a lower risk of having a GI bleed was not observed among patients receiving COX-2 inhibitors. Despite the fact that the early controlled clinical trials of the COX-2 inhibitors suggested a lower risk of GI bleed, particularly for rofecoxib, ${ }^{9-15}$ similar results were not demonstrated at the population level within this managed care setting.

The results from the present study expand on those from a cross-sectional time series analysis from 1994 through 2002 among patients older than 66 years in Ontario, Canada, where a $41 \%$ increase in NSAID utilization (resulting from the increased use of COX-2 inhibitors) was accompanied by a 10\% increase in hospitalization rates for upper GI bleed..$^{28}$ Although causation was not proven, adverse outcomes may result when 
high-risk patients who would normally not be prescribed nonselective NSAIDs are treated with COX-2 inhibitors because these medications are perceived to be safer. In the present study, the use of COX-2 inhibitors was not associated with higher rates of GI bleed for the high-risk population, and there was no measurable reduction in the risk of GI bleed for COX-2 inhibitor users compared with nonselective NSAID users.

Contrary to the findings of the present study, an earlier observational study published in 2002 examining an administrative health care database in Ontario, Canada, found a higher risk of hospitalization for a GI hemorrhage with the nonselective NSAIDs than with the COX-2 inhibitors (12.6 GI hemorrhages per 1,000 person years for nonselective NSAIDs versus 3.6 to 7.3 GI hemorrhages per 1,000 person years for COX-2 inhibitors, adjusted rate ratio ranged from 1.9 to 4.4 for nonselective NSAIDs versus COX-2 inhibitors). ${ }^{29}$ While this study was similar in concept to the present study, the 2 studies used different study populations and health systems, different cohort matching techniques, different model covariates, and different definitions of a GI bleed. The Canadian study evaluated a high-risk population (patients aged 66 years and older), while the present evaluated both low- and high-risk patients. In the Canadian study, the GI bleed outcome was limited to hospitalizations for a GI bleed, but the present study examined hospitalizations as well as outpatient claims for a GI bleed because many GI bleeds are treated in the outpatient setting (hence, the absolute rate of GI bleeds was lower in the Canadian study compared with the present study).

The Canadian study did not match nonselective NSAID users to COX-2 inhibitor users but, instead, adjusted for covariates using a Cox proportional hazards model. The covariates used within the Canadian 2002 study were different than those used in the present study. One noteworthy difference was that the Canadian study measured past history of a GI bleed over the prior 5-year period, while the present study limited this look-back period to 6 months since the frequent turnover of patients in U.S. managed care plans would not allow for a longer evaluation without significantly reducing the study sample size. While the differences in study design prohibit a direct comparison of the 2 studies, the contrasting results between the studies indicate a need for additional research to further understand the risk of GI bleed among users of COX-2 inhibitors and nonselective NSAIDs.

Whether COX-2 inhibitors are cost effective at the population level remains a controversial issue..$^{5-8,30-32}$ Based on data from this managed care organization during the fourth quarter of 2004 , the average pharmacy ingredient cost per 30 days for a COX-2 inhibitor prescription was $\$ 95.70$, which, if filled regularly for a 1-year period, would have an annual drug cost of $\$ 1,148$ per patient. In comparison, the average pharmacy ingredient cost per 30 days for a nonselective NSAID was $\$ 16.56$, or $\$ 199$ per patient per year. In other words, it would be possible to treat

\begin{tabular}{|c|c|c|c|}
\hline & $\begin{array}{c}\text { Total } \\
\text { Population } \\
(\mathrm{N}=70,014)\end{array}$ & $\begin{array}{c}\text { Low-Risk } \\
\text { Population } \\
(\mathrm{N}=29,547)\end{array}$ & $\begin{array}{l}\text { High-Risk } \\
\text { Population } \dagger \\
(\mathrm{N}=40,467)\end{array}$ \\
\hline $\begin{array}{l}\text { NSAID Selection } \\
\text { COX-2 inhibitor vs. } \\
\text { nonselective NSAID }\end{array}$ & $1.07(0.90-1.26)$ & $2.05(1.21-3.48) \ddagger$ & $0.995(0.84-1.19)$ \\
\hline $\begin{array}{l}\text { Other Factors } \\
\text { Age }\end{array}$ & $1.61(1.50-1.72) \ddagger$ & $1.25(0.97-1.62)$ & $1.53(1.39-1.68) \ddagger$ \\
\hline $\begin{array}{l}\text { Gender } \\
\text { (male vs. female) }\end{array}$ & $1.34(1.13-1.58)$ 丰 & $1.64(1.02-2.63) \neq$ & $1.31(1.09-1.56) \ddagger$ \\
\hline $\begin{array}{l}\text { State of health plan } \\
\text { Washington } \\
\text { vs. California }\end{array}$ & $0.93(0.69-1.24)$ & $0.55(0.17-1.77)$ & $0.94(0.69-1.26)$ \\
\hline Texas vs. California & $0.68(0.50-0.92) \neq$ & $0.75(0.30-1.87)$ & $0.66(0.48-0.91) \ddagger$ \\
\hline $\begin{array}{l}\text { Oregon } \\
\text { vs. California }\end{array}$ & $0.79(0.49-1.29)$ & $0.55(0.14-2.28)$ & $0.81(0.48-1.36)$ \\
\hline $\begin{array}{l}\text { Oklahoma } \\
\text { vs. California }\end{array}$ & $0.69(0.43-1.09)$ & $0.38(0.09-1.54)$ & $0.77(0.47-1.25)$ \\
\hline $\begin{array}{l}\text { Charlson } \\
\text { Comorbidity Index }\end{array}$ & $1.11(1.04-1.18) \neq$ & $1.26(1.08-1.49) \ddagger$ & $1.10(1.03-1.17) \ddagger$ \\
\hline $\begin{array}{l}\text { Corticosteroid use } \\
\text { (yes vs. no) }\end{array}$ & $1.27(0.99-1.61)$ & - & $1.20(0.94-1.54)$ \\
\hline $\begin{array}{l}\text { Warfarin use } \\
\text { (yes vs. no) }\end{array}$ & $1.75(1.39-2.19)$ \# & - & $1.68(1.33-2.12) \neq$ \\
\hline $\begin{array}{l}\text { History of GI bleed } \\
\text { (yes vs. no) }\end{array}$ & 5.35 (4.00-7.15)‡ & $10.30(5.19-20.45)$ 丰 & $4.82(3.52-6.60) \ddagger$ \\
\hline $\begin{array}{l}\text { Arthritis indication } \\
\text { Rheumatoid } \\
\text { arthritis vs. none }\end{array}$ & $1.05(0.69-1.61)$ & $1.44(0.45-4.65)$ & $0.98(0.62-1.55)$ \\
\hline $\begin{array}{l}\text { Osteoarthritis } \\
\text { vs. none }\end{array}$ & $1.10(0.91-1.32)$ & $2.01(1.10-3.67) \ddagger$ & $1.03(0.85-1.26)$ \\
\hline
\end{tabular}

* A separate regression model was performed for each of the 3 populations:

the total study population, low-risk population, and high-risk population.

$\dagger$ High-risk was defined as a patient with (a) age older than 65 years, or (b) recent history use of either warfarin or corticosteroid, or (c) a recent hospitalization for a GI bleed.

\#Indicates a level of significance of $P<0.05$.

COX -2 = cyclooxygenase $-2 ; \mathrm{GI}=$ gastrointestinal $;$ NSAID = nonsteroidal anti-inflam matory drug.

6 patients with nonselective NSAIDs for the same drug cost incurred for 1 patient taking a COX-2 drug.

Since patients using the COX-2 inhibitors did not demonstrate a reduction in GI bleeding in the present study, the cost benefit of the COX-2 inhibitors is questionable. Previous research has shown that use of COX-2 inhibitors may not be cost effective among patients with low or average GI risk, ${ }^{30}$ and the findings from the current study suggest that COX-2 inhibitors may not be cost effective even in high-risk populations. While the use of nonselective NSAIDs for high-risk patients may not be appropriate, the use of COX-2 inhibitors within high-risk populations must also be questioned. The use of COX-2 inhibitors may be appropriate for some patients; however, 
subject to the definition used to identify a case of GI bleed. A GI bleed event was defined as an inpatient hospitalization with a diagnosis representing GI bleed or at least 2 medical claims with a primary (first-listed) diagnosis representing a GI bleed. Medical records could be used to validate this definition of a GI bleed; however, examination of patient medical records was beyond the scope of this study. Further study of the accuracy of medical claims diagnoses in identifying actual GI bleeds would add to the literature. Applying a less stringent or more stringent definition for a GI bleed could have changed the study outcomes.

In order to be included in the analysis, patients were only required to have 3 months of continuous enrollment in the health plan following their fill of a COX-2 inhibitor or nonselective NSAID. While some patients could have been followed for a maximum of 1 year, others were followed for a shorter period if they disenrolled from the health plan, switched or discontinued their index class of medication (COX-2 inhibitor or nonselective NSAID), or had a GI bleed. Further research is needed to understand whether these results would have been different if patients were studied over a longer follow-up period.

While rates of concomitant use of proton pump inhibitors or other gastrointestinal protective agents were reported, an evaluation of the impact of gastroprotective agents on GI outcomes was beyond the scope of this study, which was designed to examine the relative risk of having a GI bleed among patients using COX-2 inhibitors or nonselective NSAIDs within this managed care population. Introducing the use of gastroprotective agents as a variable within the analysis could have confounded the results since the use of gastroprotective agents can represent either a risk factor or a study outcome. While the use of gastroprotective agents in combination with COX-2 inhibitors or nonselective NSAIDs merits further research, a study designed specifically to measure the concomitant use of gastroprotective agents such as a case-control study could help eliminate some of the confouning associated with this measure.

\section{Conclusion}

This study provides insight into the rates of GI bleeding among a large population of managed care patients initiated on COX-2 inhibitors or nonselective NSAIDs. Patients using a COX-2 inhibitor did not have a reduced risk of a GI bleed compared with patients with similar baseline characteristics who were using nonselective NSAIDs. With the high direct-drug cost of COX-2 inhibitors and the uncertain risk of adverse cardiovascular events, further research is needed to reevaluate the appropriate patient populations for cost-effective treatment with COX-2 inhibitors.

\section{DISCLOSURES}

No outside funding supported this study. Author Karen Stockl served as principal author of the study. Study concept and design were contributed primarily by Stockl and author Eunice Y. Chang. Analysis and interpretation of data were contributed by Stockl, Chang, and author Lori Cyprien. Drafting of the manuscript was the work of Stockl and Chang, and its critical revision was the work of Chang. Statistical expertise was contributed by Cyprien and Chang. Stockl discloses that she owns a small amount of Merck stock; Stockl, Cyprien, and Chang disclose no potential bias or conflict of interest relating to this article.

\section{REFERENCES}

1. U.S. Food and Drug Administration. FDA issues public health advisory on Vioxx as its manufacturer voluntarily withdraws the product [FDA news release. September 30, 2004]. Available at: http://www.fda.gov/bbs/topics/news/ 2004/NEW01122.html. Accessed April 29, 2005.

2. U.S. Food and Drug Administration. FDA announces important changes and additional warnings for COX-2 selective and nonselective nonsteroidal anti-inflammatory drugs (NSAIDs) [FDA public health advisory, April 7, 2005]. Available at: http://www.fda.gov/cder/drug/advisory/COX2.htm. Accessed April 29, 2005.

3. Ortiz E. Market withdrawal of Vioxx: Is it time to rethink the use of COX-2 inhibitors? J Manag Care Pharm. 2004;10(6):551-54.

4. U.S. Food and Drug Administration. Prescription nonsteroidal antiinflammatory drugs (NSAIDs) [FDA alert for health care professionals, April 7, 2005]. Available at: http://www.fda.gov. Accessed April 29, 2005.

5. Cox ER, Motheral B, Mager D. Verification of a decision analytic model assumption using real-world practice data: implications for the cost effectiveness of cyclo-oxygenase 2 inhibitors (COX-2s). Am J Manag Care. 2003;9:785-94.

6. Stacy J, Shaw E, Arledge MD, Howell-Smith D. Pharmacoeconomic modeling of prior-authorization intervention for COX-2 specific inhibitors in a 3-tier copay plan. J Manag Care Pharm. 2003;9(4):327-34.

7. Bull S, Conell C, Campen DH. Relationship of clinical factors to the use of COX-2 selective NSAIDs within an arthritis population in a large HMO. J Manag Care Pharm. 2002;8(4):252-58.

8. Curtiss FR. Cost-effective use of COX-2 drugs and NSAIDs. J Manag Care Pharm. 2002;8(4):295-96

9. Bombardier C, Laine L, Reicin A, et al. Comparison of upper gastrointestinal toxicity of rofecoxib and naproxen in patients with rheumatoid arthritis. N Engl J Med. 2000;343:1520-28.

10. Silverstein FE, Faich G, Goldstein JL, et al. Gastrointestinal toxicity with celecoxib vs. nonsteroidal anti-inflammatory drugs for osteoarthritis and rheumatoid arthritis: the CLASS study: a randomized controlled trial. JAMA. 2000;284:1247-55.

11. Langman MJ, Jensen DM, Watson DJ, et al. Adverse upper gastrointestinal effects of rofecoxib compared with NSAIDs. JAMA. 1999;282:1929-33.

12. Hawkey C, Laine L, Simon T, et al. Comparison of the effect of rofecoxib (a cyclooxygenase 2 inhibitor), ibuprofen, and placebo on the gastroduodenal mucosa of patients with osteoarthritis: A randomized, double-blind, placebocontrolled trial. Arthritis Rheum. 2000;43:370-77.

13. Laine L, Harper S, Simon T, et al. A randomized trial comparing the effect of rofecoxib, a cyclooxygenase 2-specific inhibitor, with that of ibuprofen on the gastroduodenal mucosa of patients with osteoarthritis. Gastroenterology. 1999;117:776-83

14. Simon LE, Weaver AL, Graham DY, et al. Anti-inflammatory and upper gastrointestinal effects of celecoxib in rheumatoid arthritis: a randomized controlled trial. JAMA. 1999;282:1921-28.

15. Rofecoxib (Vioxx) [prescribing information]. NDA 21-042/S-018 and NDA 21-052/S-012. Available at: http://www.fda.gov/cder/foi/label/2003/ 21042se8-018,21052se8-012_vioxx_lbl.pdf. Accessed July 27, 2005.

16. Stockl K, Vanderplas A, Tafesse E, Chang E. Costs of lower-extremity ulcers among patients with diabetes. Diabetes Care. 2004;27(9):2129-34. 
17. White TJ, Vanderplas A, Chang E, Dezii CM, Abrams GD. The costs of non-adherence to oral antihyperglycemic medication in individuals with diabetes mellitus and concomitant diabetes mellitus and cardiovascular disease in a managed care environment. Dis Manag Health Outcomes. 2004:12(3):181-88

18. Yu-Isenberg KS, Fontes CL, Wan GJ, Geissler EC, Harada AS. Acute and continuation treatment adequacy with venlafaxine extended release compared with fluoxetine. Pharmacotherapy. 2004;24(1):33-40.

19. Stockl K, Vanderplas AM, Nicklasson L. A comparison of costs for four oral antidiabetic regimens within a managed care population. Manag Care Interface. 2003;16(7):31-36.

20. Melikian C, White TJ, Vanderplas A, Dezii CM, Chang E. Adherence to oral antidiabetic therapy in a managed care organization: A comparison of monotherapy, combination therapy, and fixed-dose combination therapy. Clin Ther. 2002;24(3):460-67.

21. Celebrex NDA 20-998, approved December 31, 1998. Available at: http://www.fda.gov/cder/approval/index.htm. Accessed July 27, 2005.

22. Rubin DB. Estimating causal effects from large data sets using propensity scores. Ann Intern Med. 1997;127(8S):757-63.

23. Charlson ME, Pompei P, Ales KL, MacKenzie CR. A new method of classifying prognostic comorbidity in longitudinal studies: development and validation. J Chron Dis. 1987:40:373-83

24. Deyo RA, Cherkin DC, Ciol MA. Adapting a clinical comorbidity index for use with ICD-9CM administrative databases. J Clin Epidemiol. 1992;45: 613-19.
25. Schoenfeld D. Partial residuals for the proportional hazards regression model. Biometrika. 1982:69:239-41.

26. Grambsch P, Therneau T. Proportional hazards tests and diagnostics based on weighted residuals. Biometrika. 1994:81:515-26.

27. Therneau T, Grambsch P. Modeling Survival Data: Extending the Cox Model. New York: Springer-Verlag; 2000

28. Mamdani M, Juurlink DN, Kopp A, Naglie G, Austin PC, Laupacis A. Gastrointestinal bleeding after the introduction of COX 2 inhibitors: ecological study. BMJ. 2004:328:1415-16.

29. Mamdani M, Rochon PA, Juurlink DN et al. Observational study of upper gastrointestinal haemorrhage in elderly patients given selective cyclo-oxygenase2 inhibitors or conventional non-steroidal anti-inflammatory drugs. BMJ. 2002:325:624-29.

30. Spiegel BMR, Targownik L, Dulai GS, Gralnek IM. The cost-effectiveness of cyclooxygenase-2 selective inhibitors in the management of chronic arthritis. Ann Intern Med. 2003;138:795-806.

31. Pellissier JM, Straus WL, Watson DJ, Kong SX, Harper SE. Economic evaluation of rofecoxib versus non-selective nonsteroidal anti-inflammatory drugs for the treatment of osteoarthritis. Clin Ther. 2001;23:1061-79.

32. Feldman M, McMahon AT. Do cyclooxygenase-2 inhibitors provide benefits similar to those of traditional nonsteroidal anti-inflammatory drugs, with less gastrointestinal toxicity? Ann Intern Med. 2000;132:134-43. 